\title{
Characterization of Thermophilic Lignocellulolytic Microorganisms in Composting
}

\author{
María J. López, Macarena M. Jurado, Juan A. López-González, \\ María J. Estrella-González, María R. Martínez-Gallardo, Ana Toribio and \\ Francisca Suárez-Estrella*
}

Unit of Microbiology, Department of Biology and Geology, CIAIMBITAL Research Center, ceiA3, University of Almería, Almeria, Spain

Composting involves the selection of a microbiota capable of resisting the high temperatures generated during the process and degrading the lignocellulose. A deep understanding of the thermophilic microbial community involved in such biotransformation is valuable to improve composting efficiency and to provide thermostable biomass-degrading enzymes for biorefinery. This study investigated the lignocellulose-degrading thermophilic microbial culturome at all the stages of plant waste composting, focusing on the dynamics, enzymes, and thermotolerance of each member of such a community. The results revealed that $58 \%$ of holocellulose (cellulose plus hemicellulose) and $7 \%$ of lignin were degraded the end of composting. The whole fungal thermophilic population exhibited lignocellulose-degrading activity, whereas roughly $8-10 \%$ of thermophilic bacteria had this trait, although exclusively for hemicellulose degradation (xylan-degrading). Because of the prevalence of both groups, their enzymatic activity, and the wide spectrum of thermotolerance, they play a key role in the breakdown of hemicellulose during the entire process, whereas the degradation of cellulose and lignin is restricted to the activity of a few thermophilic fungi that persists at the end of the process. The xylanolytic bacterial isolates (159 strains) included mostly members of Firmicutes (96\%) as well as a few representatives of Actinobacteria (2\%) and Proteobacteria (2\%). The most prevalent species were Bacillus licheniformis and Aeribacillus pallidus. Thermophilic fungi (27 strains) comprised only four species, namely Thermomyces lanuginosus, Talaromyces thermophilus, Aspergillus fumigatus, and Gibellulopsis nigrescens, of whom A. fumigatus and T. lanuginosus dominated. Several strains of the same species evolved distinctly at the stages of composting showing phenotypes with different thermotolerance and new enzyme expression, even not previously described for the species, as a response to the changing composting environment. Strains of Bacillus thermoamylovorans, Geobacillus thermodenitrificans, T. lanuginosus, and $A$. fumigatus exhibiting considerable enzyme activities were selected as potential candidates for the production of thermozymes. This study lays a foundation to further investigate the mechanisms of adaptation and acquisition of new traits among thermophilic lignocellulolytic microorganisms during composting as well as their potential utility in biotechnological processing. 


\section{INTRODUCTION}

Lignocellulosic materials, including agricultural and forestry waste, are defined as a valuable renewable carbon resource in the implementation of current biorefineries supported by Circular Economy. Its use is therefore considered as a useful and environmentally friendly alternative to traditional refineries based on the use of raw materials (RMs) derived from oil (Hemati et al., 2018). Some microorganisms have evolved different enzyme systems with specific catalytic strategies to degrade complex lignocellulose. In fact, lignocellulose depolymerization in natural ecosystems is highly efficient because of the synergistic action of multiple enzymes produced by taxonomically distinct microorganisms. For example, aerobic organisms, such as Trichoderma species and numerous actinomycetes, produce and secrete free lignocellulolytic enzymes, whereas anaerobic bacteria, such as Clostridium thermocellum and Acetivibrio cellulolyticus, integrate various cellulases (Cels) and xylanases (Xyls) into a large multienzyme complex (Bhalla et al., 2013).

One of the preferred environments for the recovery of lignocellulose-degrading microorganisms is the composting process (Jurado et al., 2014; Harindintwali et al., 2020). It has been extensively analyzed in order to determine the role of this specific group of microorganisms in the deconstruction of this type of recalcitrant polymer. Composting has been positioned for the last 25 years as a successful alternative for the treatment of organic waste, in which the biotransformation process is carried out by a complex microbial community (Schaub and Leonard, 1996; Insam and de Bertoldi, 2007; Moreno et al., 2021). During the process, heat is produced because of the energy generated by exergonic aerobic reactions derived from microbial metabolism. This leads the composting to evolve through different stages driven mainly by the temperature reached in the materials being transformed. The thermal phases that define a composting process are mesophilic, thermophilic, cooling, and maturation. Microbial activity is more intense during the first two stages (bio-oxidative phase), whereas the humification of the materials occurs mainly during the final phases of the process (maturation phase) (Villar et al., 2016). Temperature, therefore, will determine the structure and dynamics of microbial populations throughout composting, being also a key factor commonly used to confirm the process is running properly. Numerous data support that the temperature reached inside a composting pile favors the selection of an extremophile thermotolerant microbiota capable of intervening in the carbon and nitrogen recycling, acting on the lignocellulosic complex structure (Jurado et al., 2014; Hemati et al., 2018; Ince et al., 2020). Therefore, based on recent investigations, most microorganisms in composting could be defined as thermotolerant, as they become adapted to the changing temperature of the process (Moreno et al., 2021). These thermotolerant microorganisms are of special interest because of the thermostability of their enzymes (Bhalla et al., 2013), which makes them more competitive in industrial processes, compared to other more thermolabile microorganisms (Hemati et al., 2018).
During the last years, numerous authors have highlighted the biotechnological relevance of the populations of thermophilic organisms present in the composting process (Jurado et al., 2014; Ince et al., 2020). In fact, recent advances in molecular identification, metagenomics, and proteomics have made it possible to understand the metabolic diversity and functionality of different fungal and bacterial families involved in the process, in terms of their ability to degrade lignocellulosic fractions. In some cases, an approximation at the genus or even species level has been possible, showing a detailed profile of the microbiome of the composting piles, extremely dependent on the RMs and the operating conditions applied in each case (Langarica-Fuentes et al., 2014; Estrella-González et al., 2020; Ince et al., 2020). Other authors have described the capacities of microbial consortia from the "secretome" of lignocellulosic materials subjected to different thermal treatments, suggesting a metabolic coordination between different species with a view to deconstruction of the lignocellulose (Gavande et al., 2021). In any case, most of the studies described, although novel because they are based on the use of genomic mining and powerful data platforms, do not allow knowing the thermal tolerance range of the identified taxa, nor the actual capacity to deconstruct lignocellulosic fractions.

Therefore, the objectives of this work were: (i) to quantify thermophilic microorganisms and their lignocellulolytic representatives during a plant waste-based composting process, in parallel to the analysis of the evolution of the degradation of the lignocellulose; (ii) to analyze the ability to degrade cellulose (CEL), hemicellulose (HC), and lignin (LIG), the range of thermal tolerance, and identity by sequencing of the lignocellulolytic thermophilic bacteria and fungi from the different stages of the process; and (iii) to select specific strains with potential application for the production of thermostable enzymes.

\section{MATERIALS AND METHODS}

\section{Composting and Sampling Strategy}

The composting parameters and procedure were performed according to López-González et al. (2013). A composting pile of 3.0 -m length $\times 1.5-\mathrm{m}$ width $\times 1.0-\mathrm{m}$ height was prepared by mixing shredded $(<3 \mathrm{~cm})$ tomato plant waste (stalks and leaves) with pine chips (50:50 wt/wt) in order to get a carbon-to-nitrogen ratio around 25. The pile was subjected to forced aeration (7.5$9.0 \mathrm{~L} / \mathrm{kg}$ every $4 \mathrm{~h}$ ) to maintain oxygen concentration inside the pile over $10 \%$. The air was supplied from the bottom of the pile through perforated PVC tubes connected to a Lowarda CEAM-7013 pump (Montecchio Maggiore, Italy). Turnings were performed using a tractor shovel when the temperature inside the pile dropped for three consecutive days (approximately every week). The moisture content was initially set between 50 and $55 \%$ (wt/wt), and it was maintained within this range by watering during turning operations. These management operations were applied during the bio-oxidative phase (2 months) until the material cooled down. After this period, the piles were statically maintained in maturation for an additional period (4 months), so the process lasted for a total of 6 months. Temperature values 
inside the piles were continuously measured using a $50-\mathrm{cm}$ long Pt 100 temperature probe model MPT2 (Lexitron-Guemisa, Madrid, Spain) connected to a data logger.

Samplings were carried out at different stages of the composting process, according to the thermal values prevailing inside the piles, including RMs, mesophilic stage (MES), thermophilic stage (THER), cooling stage (COOL), maturation stage (MAT), and final product (Table 1). Composite samples (500 g) were collected at each sampling time by properly mixing and homogenizing subsamples extracted from nine different locations inside each pile. Each sample was divided into two equal parts; one of them was kept at $4^{\circ} \mathrm{C}$ for further chemical analysis, whereas the second portion was immediately used for the microbiological analyses.

\section{Characterization of Solid Compost Samples: Lignocellulosic Fractions}

Cellulose, HC, and LIG fractions were determined using a fiber analyzer ANKOM200/220 (Ankom Technology, United States) according to the methods established by Ankom Technology for Acid Detergent Fiber, Neutral Detergent Fiber, and Acid Detergent Lignin. ${ }^{1}$ Holocellulose was expressed as the sum of CEL and HC values. Losses of lignocellulosic fractions (HC, CEL, and LIG) were calculated from the initial (A1) and final (A2) ash contents according to the equation of Paredes et al. (2000), where P1 and P2 were the initial and final concentrations of lignocellulose fraction $(\mathrm{mg} / \mathrm{g})$.

$$
\% \text { Loss }=100-100 \times((\mathrm{A} 1 \times \mathrm{P} 2) /(\mathrm{A} 2 \times \mathrm{P} 1))
$$

\section{Analysis of Thermophilic Microorganisms}

\section{Counts, Isolation, and Maintenance of Microorganisms}

Suitable culture media and incubation temperatures were employed for the isolation and enumeration of thermophilic

${ }^{1}$ http://www.ankom.com/procedures.aspx

TABLE 1 | Sampling times and main characteristics of material.

\begin{tabular}{lccccc}
\hline $\begin{array}{l}\text { Composting } \\
\text { stage }^{*}\end{array}$ & Day & $\begin{array}{c}\text { Temperature } \\
\left({ }^{\circ} \mathbf{C}\right)\end{array}$ & $\begin{array}{c}\text { Organic } \\
\text { matter }(\%)\end{array}$ & $\mathbf{C} / \mathbf{N}^{\star * *}$ & $\mathbf{p H}$ \\
\hline RM & 0 & $24.1 \pm 2.3$ & $65.9 \pm 3.5$ & $27.7 \pm 2.4$ & $7.9 \pm 0.1$ \\
MES & 5 & $41.8 \pm 5.1$ & $62.1 \pm 2.1$ & $24.3 \pm 1.0$ & $8.7 \pm 0.1$ \\
THER & 16 & $59.4 \pm 6.0$ & $61.5 \pm 2.6$ & $24.3 \pm 0.9$ & $8.5 \pm 0.2$ \\
COOL & 63 & $36.1 \pm 3.4$ & $60.7 \pm 2.0$ & $21.1 \pm 1.1$ & $8.6 \pm 0.1$ \\
MAT & 168 & $27.4 \pm 1.4$ & $50.9 \pm 4.1$ & $15.9 \pm 2.1$ & $8.6 \pm 0.1$ \\
FP & 189 & $20.6 \pm 1.0$ & $43.9 \pm 2.2$ & $13.3 \pm 0.7$ & $8.5 \pm 0.1$
\end{tabular}

*Composting stage: RM, raw material; MES, mesophilic; THER, thermophilic; COOL, cooling; FP, final composting product.

**Temperature values are the mean and SD for the period between the corresponding stage and the previous one (except for RM in which average values of the same material are included $n=3$ ).

${ }^{* * *} \mathrm{C} / \mathrm{N}$, carbon-to-nitrogen ratio reached at each stage. strains. Besides bacteria and fungi, the specific bacterial group of actinobacteria was analyzed separately because of its important role in the degradation of lignocellulose during composting (Steger et al., 2007; Jurado et al., 2014). Thermophilic actinobacteria were cultured in Actinomycete Isolation Agar Glycerol (Difco, Becton, Dickinson \& Co., MD, United States) and incubated at $55^{\circ} \mathrm{C}$ for $4-5$ days. Thermophilic bacteria were cultured in standard Nutrient Agar (NA; Cultimed, Spain) at $55^{\circ} \mathrm{C}$ for $2-3$ days. Thermophilic fungi were cultured in Rose Bengal Chloramphenicol Agar plates (Cultimed, Spain) at $55^{\circ} \mathrm{C}$ for 4-5 days. Fresh samples (10 g) were suspended in $90 \mathrm{~mL}$ sterile saline solution $(0.9 \% \mathrm{NaCl}$ in distilled water) and shaken [150 revolutions/min ( $\mathrm{rpm})$ ] at room temperature for $30 \mathrm{~min}$. Then, 10-fold serial dilutions in sterile saline solution were performed, and $100 \mu \mathrm{L}$ from dilutions was spread out over Petri plates with the required culture media. Counts were expressed as colony-forming units per gram of sample dry weight [colonyforming units (CFU)/g]. Each different colonial type (according to size, morphology, pigmentation, and texture) in each plate was separately counted and then transferred to a new plate with fresh medium. Plates were incubated (same times and temperatures as before indicated), checked for purity, and stored at $4^{\circ} \mathrm{C}$ (working pure cultures) or preserved in cryoballs Cryoinstant (Deltalab, Spain) for long-term conservation. Pure cultures were photographed, and all morphotypes were compared. In addition, microscopic observations, Gram and spore stains, and catalase and oxidase tests (Gerhardt et al., 1994) were performed in order to eliminate repeated isolates.

\section{Microbial Enzymatic Profile: Cellulolytic, Xylanolytic, and Ligninolytic Activity}

The isolated microorganisms were tested for the expression of ligninolytic (Lig), cellulolytic (Cel), and xylanolytic (Xyl) activities. All the assays were performed on plates with solid medium containing the appropriate substrate for the specific activity as described below. For bacteria and actinobacteria, the plates were inoculated with $25 \mu \mathrm{L}$ droplets of biomass suspension made in $500 \mu \mathrm{L}$ sterile saline solution $(\mathrm{NaCl} 0.9 \%)$ from microorganism grown on one APHA (Cultimed, Spain) agar slant for 48 to $72 \mathrm{~h}$. In the case of fungi, pieces of 6-mm diameter from a 96-h culture on PDA (Potato Dextrose Agar, Scharlab, Spain) were placed in the plates. The inoculated media were incubated at $50^{\circ} \mathrm{C}$ for 5 days (Xyl activity) and 7-10 days (Cel and Lig enzyme activities) and checked for the presence of the activity. Cel and Lig microorganisms showed decolorization around the colony grown on $0.5 \%$ CEL plus $0.005 \%$ aniline blue black (Kauri and Kushner, 1988) and Poly R-478-containing (Freitag and Morrell, 1992) agar plates, respectively. A clear halo around colonies demonstrated Xyl activity on $0.5 \%$ (wt/vol) xylan-containing medium.

\section{Thermotolerance Profiles of Isolates}

The range of growth temperatures and optimal growth temperature of strains within the thermal interval of 20,30, 40, 50 , and $60^{\circ} \mathrm{C}$ was determined according to Moreno et al. (2021). Plates of NA (Scharlab, Spain) (bacteria) or PDA (fungi) were inoculated by streaking sterile swabs previously soaked in fresh 
liquid cultures on NB (bacteria) or PDB (fungi). After incubation at the different temperatures for 48-72 h (bacteria), $96 \mathrm{~h}$ (fungi), and 96-120 h (actinobacteria), tests were considered positive when visible microbial growth was evident, so a range of growth temperature was determined. To determine optimal microbial growth at the selected temperatures, a microtiter assay based on Resazurin reduction was employed as described by Moreno et al. (2021) based on the procedure proposed by Chadha and Kale (2015) and Vega et al. (2012). Three replicates were used for each combination strain/temperature.

\section{Production and Quantification of Xyl, Cel, and Ligninase Enzymatic Activities}

Xylanase and Cel production were induced by culturing selected microorganisms in 100-mL flasks with $20 \mathrm{~mL}$ minimal salt medium (Janshekar et al., 1982), added to 0.5\% (wt/vol) beechwood xylan (Apollo Scientific) or carboxymethylcellulose (CMC) (Sigma-Aldrich) as the sole carbon and energy source, respectively. For the production of ligninases, i.e., laccase (Lac), LIG peroxidase (LiP), and manganese peroxidase (MnP), $20 \mathrm{~mL}$ of Kirk medium (Kirk et al., 1986) that contained veratryl alcohol as inducer, was used. The production media were inoculated with $1-\mathrm{cm}^{2}$ plug of a 7-day-old fungal mycelium precultured in PDA (Potato Dextrose Agar, Scharlab, Spain) or 2\% (vol/vol) bacterial suspensions in $0.9 \% \mathrm{NaCl}$ with $\mathrm{OD}_{600} 0.5$ from a preculture incubated at $50^{\circ} \mathrm{C}$ in NA (Scharlab, Spain). Cultures were incubated at $50^{\circ} \mathrm{C}$ statically (fungi) or shaking at $110 \mathrm{rpm}$ (bacteria), for 7 days. After the incubation time, $10 \mathrm{~mL}$ was centrifuged at $10,000 \mathrm{~g}$ for $10 \mathrm{~min}$ to obtain the supernatant with the crude extract in which the enzymatic activities were analyzed.

Xylanolytic and Cel activities were determined by measuring the reducing sugars released using the 3,5-dinitrosalicylic acid (DNS) method, with xylose and glucose as standard, respectively (Miller, 1959). Xyl reaction mixture contained $250 \mu \mathrm{L}$ of the crude enzymatic extract and $250 \mu \mathrm{L}$ of substrate consisting of $1 \%$ (wt/vol) beechwood xylan (Sigma) in phosphate-citrate buffer (50 mM at pH 6.5) (He et al., 1993). Cel reaction mix consisted of $250 \mu \mathrm{L}$ crude enzymatic extract and $250 \mu \mathrm{L}$ of substrate containing 1\% (wt/vol) sodium CMC (Sigma) in sodium acetate buffer (50 $\mathrm{mM}$ at $\mathrm{pH}$ 5). Controls were prepared with enzyme added after DNS reagent addition $(1.5 \mathrm{~mL})$. After incubation at $50^{\circ} \mathrm{C}$ for $1 \mathrm{~h}$, the released reducing sugars were assayed by DNS method spectrophotometrically estimated (Shimadzu UV-160A) at $550 \mathrm{~nm}$. One unit of Xyl and Cel activities (U) was defined as the amount of enzyme required to release $1 \mu \mathrm{mol}$ of xylose and glucose, respectively, per minute under assay conditions.

Laccase, LiP, and MnP were analyzed in reactions with a final volume of $2 \mathrm{~mL}$. Lac was determined by monitoring the oxidation of syringaldazine at $525 \mathrm{~nm}$ for $2 \min \left(\varepsilon 525=65,000 \mathrm{M}^{-1} \mathrm{~cm}^{-1}\right)$ (Orth et al., 1993). The reaction mixture comprised $200 \mu \mathrm{L}$ syringaldazine $(0.216 \mathrm{mM}), 500 \mu \mathrm{L}$ citrate-phosphate buffer (400 mM, pH 5.2), and $500 \mu \mathrm{L}$ enzymatic extract. LiP was performed by measuring the oxidation of veratryl alcohol to veratraldehyde at $310 \mathrm{~nm}$ for $2 \min \left(\varepsilon 310=9,300 \mathrm{M}^{-1} \mathrm{~cm}^{-1}\right)$ (Orth et al., 1993). The reaction mixture contained $200 \mu \mathrm{L}$ veratryl alcohol $(20 \mathrm{mM}), 200 \mu \mathrm{L}$ sodium tartrate buffer (250 mM, pH 2.5), $200 \mu \mathrm{L}$ hydrogen peroxide solution (4 mM), and $500 \mu \mathrm{L}$ enzymatic extract. $\mathrm{MnP}$ activity was performed by measuring the oxidation of $\mathrm{Mn}^{2+}$ to $\mathrm{Mn}^{3+}$ at $238 \mathrm{~nm}$ $\left(\varepsilon 238=6,500 \mathrm{M}^{-1} \mathrm{~cm}^{-1}\right)$ (Camarero et al., 1999). The reaction volume contained $200 \mu \mathrm{L}$ manganese sulfate $(1 \mathrm{mM}), 200 \mu \mathrm{L}$ sodium tartrate buffer ( $1 \mathrm{M}, \mathrm{pH} 5), 200 \mu \mathrm{L}$ hydrogen peroxide solution $(1 \mathrm{mM})$, and $500 \mu \mathrm{L}$ enzymatic extract. All enzymes assays were carried out using a UV array spectrophotometer (Shimadzu UV-160A). One unit of enzyme activity was defined as the enzyme required for the formation of $1 \mu \mathrm{M}$ of the product per minute under the conditions of the reaction.

\section{Identification of Microorganisms}

The identification protocol was based on partial or nearly full-length 16S rRNA gene (bacteria, including actinobacteria) and 5.8S-ITS region (yeast and fungi) sequence analysis. The $16 \mathrm{~S}$ rRNA genes of bacteria were amplified using universal primers: 27F ( $5^{\prime}$-AGAGTTTGATCATGGCTCAG-3') and 1492R (5'-GGTTACCTTGTTACGACTT-3') (Weisburg et al., 1991). The 5.8S-ITS region of fungi and yeast was amplified using primers ITS1 (5'-TCCGTAGGTGAACCTGCGG-3') and ITS4 (5'-TCCTCCGCTTATTGATATGC-3') (White et al., 1990). Amplified PCR products were checked by gel electrophoresis on $1 \%$ agarose gel and purified using the Diffinity Rapid Tips (Sigma-Aldrich). The clean DNA was sequenced by capillary sequencer ABI Hitachi 3500 Genetic Analyzer (Applied Biosystems). The forward and reverse sequences were edited, assembled, and aligned using Sequence Scanner v1.0 (Applied Biosystem), Reverse Complement, ${ }^{2}$ Clustal Xv2.0.11 (Larkin et al., 2007), and MEGA 5 v5.2 (Tamura et al., 2011). The sequences were then compared for similar nucleotide sequences with the BLAST search of the National Center of Biotechnology Information (NCBI). ${ }^{3}$

\section{Data Analysis}

Three independent replicates were used in all analyses, and the data obtained were subjected to statistical analysis using Statgraphics Centurion XVIII (StatPoint, Inc., Virginia). Welch analysis-of variance and Games-Howell multiple comparisons were applied to compare mean values of the optimal growth temperature of the microorganisms for the different levels of composting stage or taxon.

\section{RESULTS AND DISCUSSION}

\section{Abundance of Lignocellulose-Degrading Thermophiles During Composting and Degradation of Lignocellulosic Fractions}

Thermophilic bacteria, actinobacteria, and fungi at each composting stage, as well as the levels of lignocellulolytic representatives for each group, are shown in Figure 1 (Supplementary Table 1). Total thermophilic bacteria and actinobacteria peaked at MES and THER and maintained

\footnotetext{
${ }^{2}$ www.bioinformatics.org/sms/rev comp.html

${ }^{3}$ http://blast.ncbi.nlm.nih.gov/Blast.cgi
} 


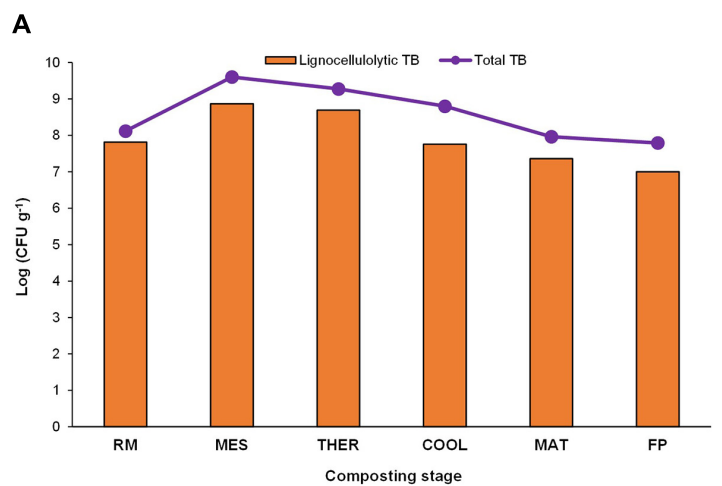

C

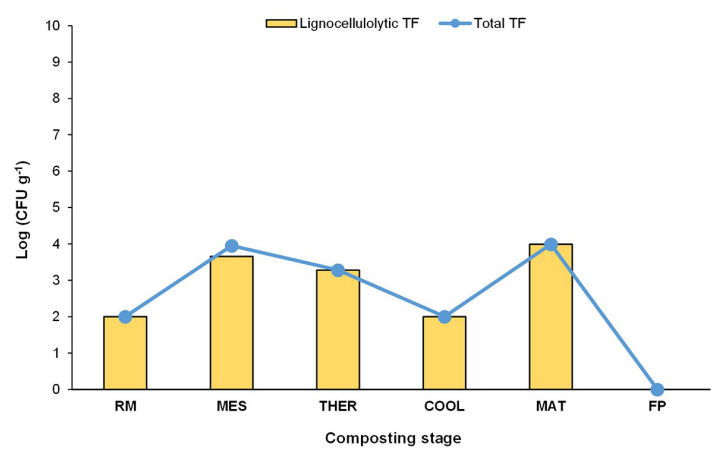

B

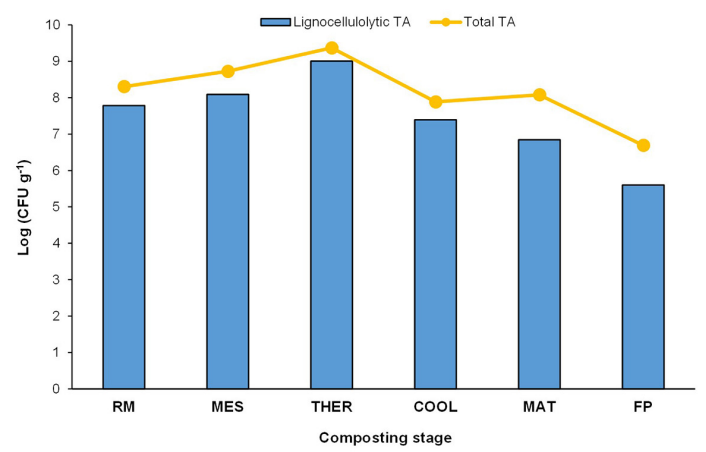

D

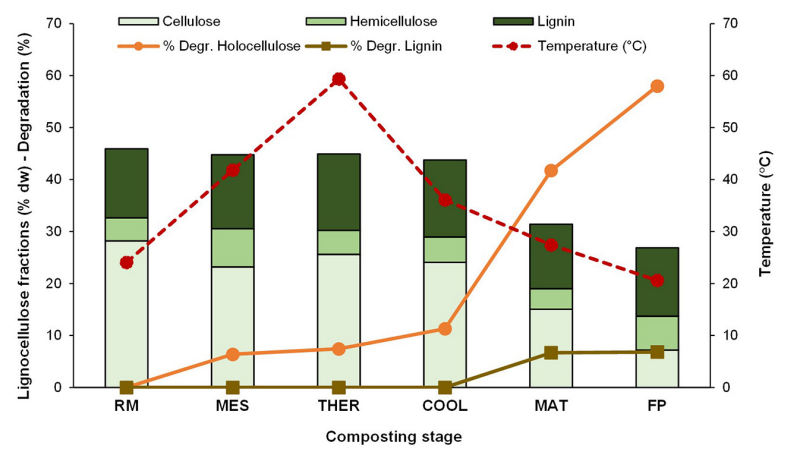

FIGURE 1 | Counts of total and lignocellulolytic thermophilic (A) bacteria (TB), (B) actinobacteria (TA), and (C) fungi (TF). (D) Thermal values and lignocellulose fraction content (\%) and degradation (\%). Composting stage: RM, raw material; MES, mesophilic; THER, thermophilic; COOL, cooling; FP, final composting product.

\section{A}

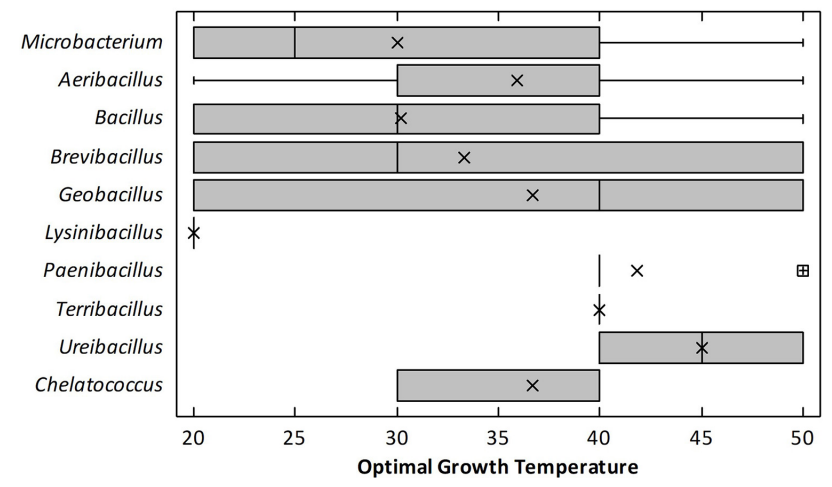

B

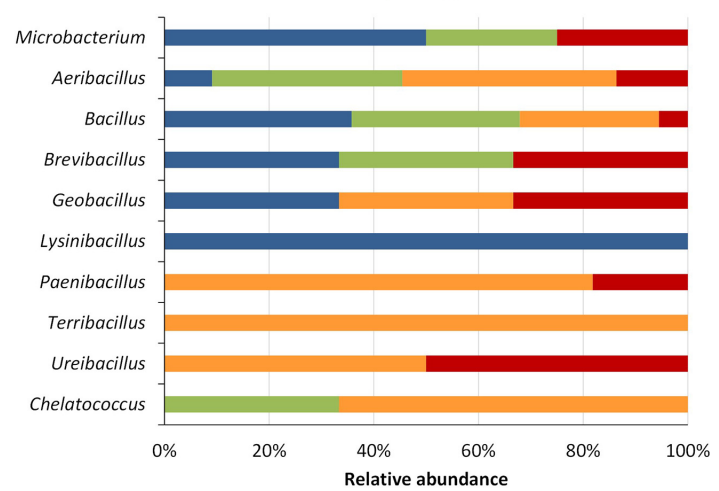

FIGURE 2 | Optimal growth temperatures of the thermophilic xylanolytic bacterial genus isolated from compost. (A) Box-and-whisker plot summarizing the range of optimal growth temperature for the different strains of each genus; mean values (x), median (I), and outliers $(\square)$ are represented; (B) relative abundance of xylanolytic strains for each genus having the optimal growth temperature: $20^{\circ} \mathrm{C}(X-20), 30^{\circ} \mathrm{C}(X-30), 40^{\circ} \mathrm{C}(X-40)$, and $50^{\circ} \mathrm{C}(X-50)$.

high values, in the range of $10^{6}-10^{8} \mathrm{CFU} / \mathrm{g}$, throughout the process. In contrast, thermophilic fungi were far less abundant, with levels not exceeding a maximum of $10^{3} \mathrm{CFU} / \mathrm{g}$ at $\mathrm{MES}$ and THER, and were absent in the final compost likely because of competition with mesophilic microbial population (López-González et al., 2015; Moreno et al., 2021). Noteworthy was the fact they experienced a final increase at MAT, after decreasing at COOL, which is a trend also reported earlier in composting of anaerobic digestates (Di Piazza et al., 2020). The thermophilic lignocellulolytic bacteria and actinobacteria count was approximately $10 \log$ units lower than total thermophilic but showed the same trend at the composting stages (Figures 1A, B). In the case of fungi, the lignocellulolytic population was nearly $100 \%$ of the total thermophilic fungi counts (Figure 1C). Although thermophilic microorganisms are not uniquely responsible for the biodegradation of lignocellulose during 
A

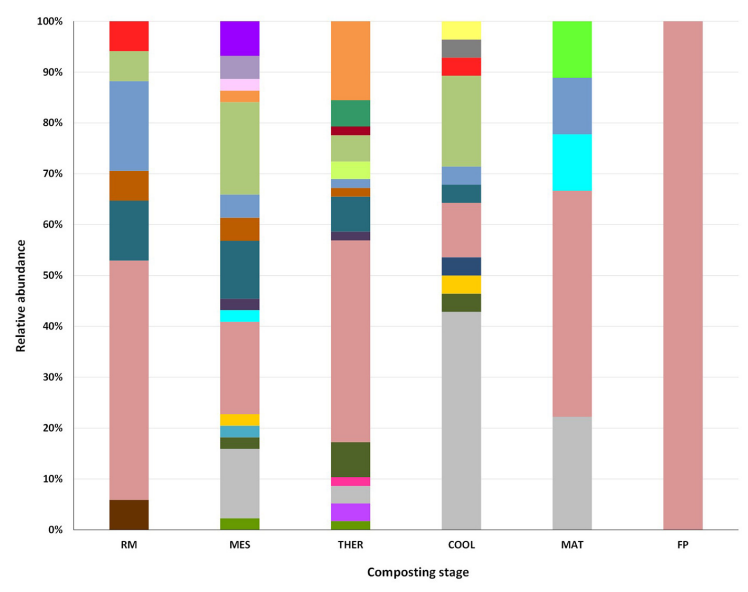

B

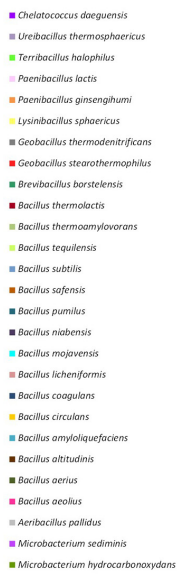

C
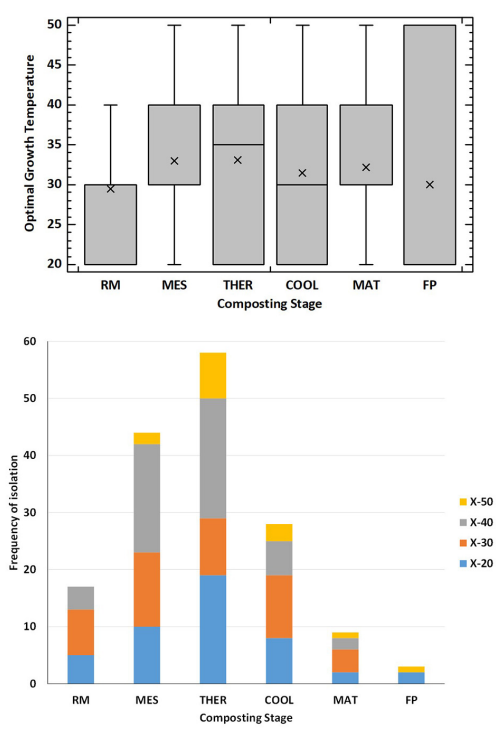

FIGURE 3 | Thermophilic xylanolytic bacterial strains at the different stages of composting. (A) Relative abundance of the species; (B) Box-and-whisker plot with the range of optimal growth temperature for the different strains, mean values (X), median (I) and outliers ( $\square$ ) are represented; (C) frequency of isolation of the bacterial phenotypes: xylanolytic strains with optimal growth at $20^{\circ} \mathrm{C}(X-20), 30^{\circ} \mathrm{C}(X-30), 40^{\circ} \mathrm{C}(X-40)$ and $50^{\circ} \mathrm{C}(X-50)$. Composting stage: RM, raw material; MES,

mesophilic; THER, thermophilic; COOL, cooling; FP, final composting product.

composting, they play a key role because they actively grow at the THER when it has been reported that lignocellulose degrades at a faster rate (Xiao et al., 2009; Qiao et al., 2019). In the present study, the degradation of holocellulose (sum of CEL and HC) took place mainly after COOL, reaching a net value of $58 \%$ at the end (Figure 1D) (Supplementary Table 1). It started from the early composting, at MES (6\%), and slightly increased right after THER. Considering that MES and THER lasted for 5 and 11 days, respectively, and the time between cooling and the final composting product was 126 days (Table 1), the faster holocellulose degradation occurred at MES, when the daily degradation rate was 1.5 , in contrast with the later period in which the value was 0.5. Notwithstanding this, it is at THER when the thermophilic microorganisms are the unique active organisms and the sole ones responsible for the degradation of the lignocellulose that could lead to loosening its structure facilitating further degradation. Noticeably, the degradation of LIG was negligible up to MAT in which $7 \%$ of this polymer was degraded, an activity that matched with the late increase of thermophilic fungi counts.

\section{Lignocellulolytic Thermophilic Bacteria and Fungi}

The thermophilic isolates having lignocellulose-degrading activity consisted of 186 strains, including 159 bacteria and 27 fungi, for whom the specific composting stage when they were obtained was known. Bacterial strains only had Xyl activity, whereas among the fungi, Cel and Lig activities were also found for some strains. All isolates were identified by sequencing $16 \mathrm{~S}$ rRNA or 5.8S-ITS region for bacteria and fungi, respectively. In addition, the range of growth at temperatures between
20 and $60^{\circ} \mathrm{C}$ as well as the optimal temperature for growth was determined for each isolate. Publicly available datasets analyzed in this study can be found in Mendeley Data, V1 (doi.org/10.17632/265tjt9f4m.1).

The Xyl bacterial isolates included mostly members of the phylum Firmicutes (96\%), besides a few representatives of the phyla Actinobacteria (2\%) and Proteobacteria (2\%) (Supplementary Table 2). Actinobacteria strains were identified as Microbacterium hydrocarbonoxydans and Microbacterium sediminis, whereas the Proteobacteria were all Chelatococcus daeguensis. Within the Firmicutes, there were representatives of 24 species belonging to seven genera, all of the Class Firmicutes, with a clear dominium of Bacillus (109 strains) followed by Aeribacillus (22 strains), Paenibacillus (11 strains), Brevibacillus (3 strains), Geobacillus (3 strains), Ureibacillus (2 strains), Lysinibacillus (1 strain), and Terribacillus (1 strain). Among the 27 different species detected, most isolates (70\%) belonged to five of them: Bacillus licheniformis (49 strains), Aeribacillus pallidus (22 strains), Bacillus thermoamylovorans (17 strains), Bacillus pumilus (12 strains), and Paenibacillus ginsengihumi (10 strains). Approximately $87 \%$ of the bacterial strains grew at thermotolerant temperature ranges $\left(20-60^{\circ} \mathrm{C}\right)$, whereas $4 \%$ could be considered true thermophiles, i.e., those unable to grow at temperatures below $40^{\circ} \mathrm{C}$. These included members of the species $A$. pallidus and $B$. thermoamylovorans. The dominium of thermotolerant microorganisms during composting has been already demonstrated for the total microbial population (Moreno et al., 2021) and also applies to thermophilic Xyl bacteria. The variations in optimal growth temperature obtained for the different strains of each genus are shown in Figure 2A. Approximately $50 \%$ of the isolates grew optimally at $40^{\circ} \mathrm{C}$ or $50^{\circ} \mathrm{C}$ (Figure 2B). The largest variability for this trait 
was obtained for strains of the genera from the phylum Firmicutes, Brevibacillus, Geobacillus, Bacillus, Aeribacillus, and the Actinobacteria Microbacterium, which had representatives in both extremes of the temperatures tested. All these Firmicutes genera have been earlier reported to grow in a wide range of temperatures (Bhattacharya and Pletschke, 2014; Verma et al., 2019), but Microbacterium usually grows at temperature lower than $44^{\circ} \mathrm{C}$ (Fidalgo et al., 2016). Chelatococcus strains were optimal at $30^{\circ} \mathrm{C}$ and $40^{\circ} \mathrm{C}$, whereas it was over $40^{\circ} \mathrm{C}$ for the strains of the genera Paenibacillus, Terribacillus, and Ureibacillus. The unique representative of Lysinibacillus had optimal growth at $20^{\circ} \mathrm{C}$ (Figure $\mathbf{2 A}$ ), that is, in the range of growth temperature of the genus $\left(16^{\circ} \mathrm{C}-45^{\circ} \mathrm{C}\right.$ ) (Ahmed et al., 2007). Xyl activity, thermotolerance, and thermophilia are common traits among Firmicutes, especially for bacilli and related genera (Bhattacharya and Pletschke, 2014). In fact, Geobacillus, Paenibacillus, and Bacillus, our predominant isolates, are the most widely reported thermophilic bacteria for their ability to produce thermostable Xyl (Verma et al., 2019). Noteworthy, the second most abundant bacilli isolate, A. pallidus (formerly Geobacillus pallidus), is thermophilic and alkalitolerant (Minana-Galbis et al., 2010) for whom no Xyl activity has been reported in prior studies. That also applies to the Alphaproteobacteria C. daeguensis, a typical mesophilic bacteria (Yoon et al., 2008), for which thermophilic strains have been recently reported (Wei et al., 2017) while having no Xyl activity detected to date. Actinobacteria also harbor Xyl enzymes; although Microbacterium is not the typical genus of that phylum for such activity, some strains having Xyl activity have been isolated from cricket gut (Kim et al., 2014). No Cel and Lig activity was found among the bacterial isolates, but this requires a deeper screening. Thermophilic bacteria belonging to Bacillus and Geobacillus are known to produce thermostable Cels (Patel et al., 2019) and the LIG-degrading enzyme Lac (Bugg et al., 2011; Chauhan et al., 2017).

Considering the different stages of composting, the widest number of thermophilic bacterial Xyl strains and the largest diversity of species were obtained from mesophilic (44 strains of 16 species) and thermophilic (58 strains of 15 species) stages, whereas at maturation and final composting product, only nine strains of five species and three strains of one species, respectively, showed $\mathrm{Xyl}$ activities (Figure 3A). The unique Proteobacteria, C. daeguensis, was recovered from the MES. The two species of Actinobacteria, M. hydrocarbonoxydans and $M$. sediminis, were isolated from MES and THER, whereas the species of the phylum Firmicutes dominated over all stages. $B$. licheniformis strains accounted for $50 \%$ of isolates, except at MES and COOL. At the MES, A. pallidus, B. licheniformis, and $B$. thermoamylovorans together represented $50 \%$, whereas at the COOL, A. pallidus dominated. In the final composting product, only $B$. licheniformis was isolated. Furthermore, the optimal mean growth temperature of the strains, as well as the range of phenotypes for such traits, showed a tendency to increase throughout the process (Figure 3B). This clearly relates to the adaptation of the microbial community to the thermal variations

TABLE 2 | Thermal phenotypes of thermophilic xylanolytic bacterial strains with the same accession number detected at the different composting stages: RM, raw material; MES, mesophilic; THER, thermophilic; COOL, cooling; FP, final composting product.

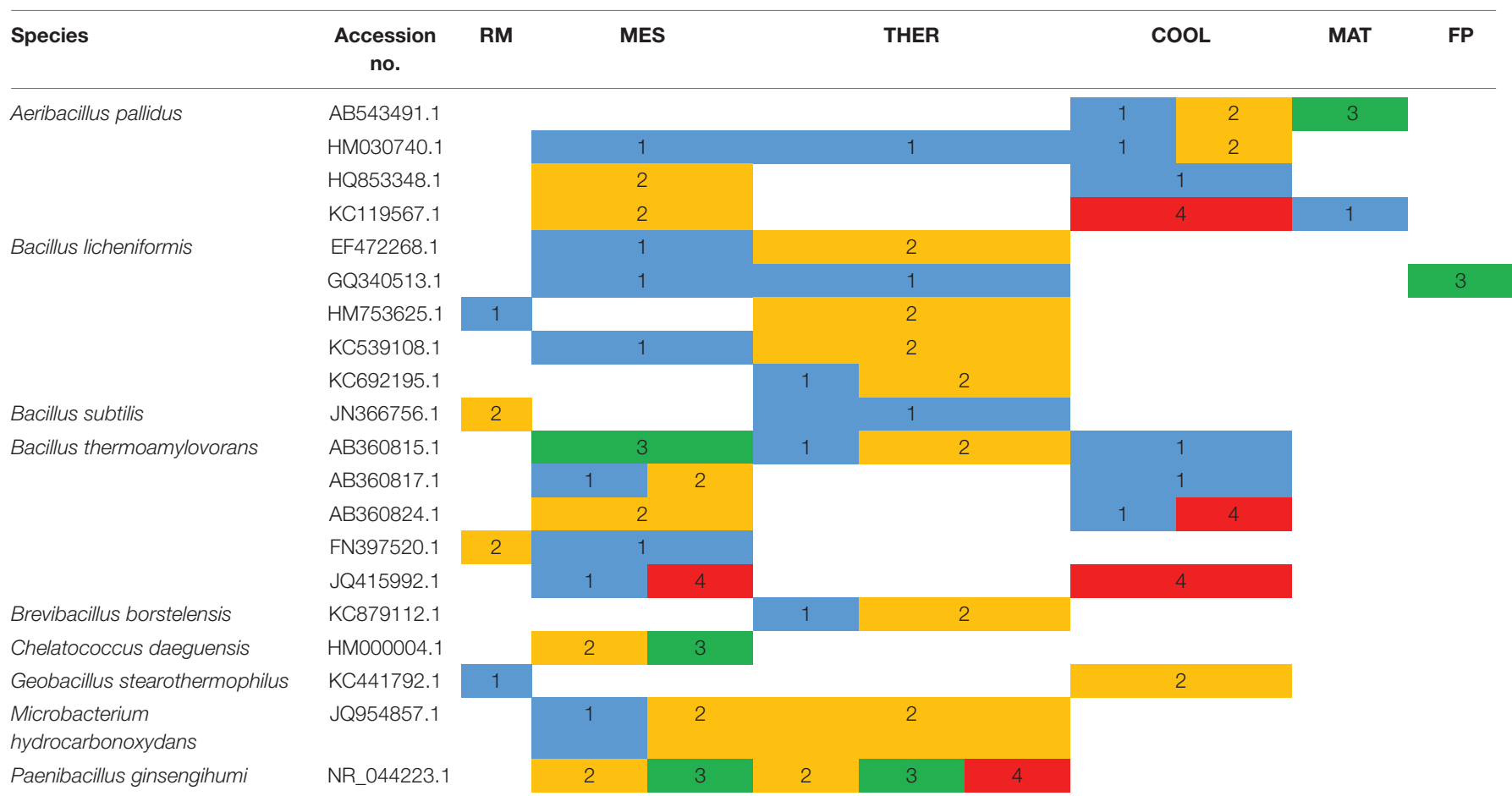

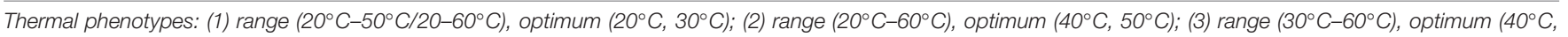
$\left.50^{\circ} \mathrm{C}\right)$; (4) range $\left(40^{\circ} \mathrm{C}-60^{\circ} \mathrm{C} / 50^{\circ} \mathrm{C}-60^{\circ} \mathrm{C}\right)$, optimum $\left(40^{\circ} \mathrm{C}, 50^{\circ} \mathrm{C}\right)$. 
during composting (Moreno et al., 2021). The strains isolated from the RMs had an optimal growth average of $30^{\circ} \mathrm{C}$ with the maximum at $40^{\circ} \mathrm{C}$. From the MES, the average temperature increased and the optimal growth temperature among the strains covered the whole range tested. The phenotypes with optimal growth at $50^{\circ} \mathrm{C}$ appeared at the MES and, as expected, increased at thermophilic to decrease again at cooling and maturation, but even at these cold stages, they were present (Figure 3C). The phenotypes having optimal growth temperature at or greater than $40^{\circ} \mathrm{C}$ represented $50 \%$ of the isolates at MES and THER and approximately $30 \%$ in the other stages. Thus, Firmicutes account for the most prevalent group of Xyl thermophiles during composting, being represented by diverse members of the genus Bacillus. They also have a wide spectrum of thermostability, which allows them to survive and remain metabolically active over all stages. Consequently, this group should play a crucial role in the breakdown of HC during the entire process. Similar conclusions have been obtained using metagenomics analysis (Antunes et al., 2016; Gavande et al., 2021). Furthermore, it was noticeable that many bacterial isolates having the same accession number showed different thermal phenotypes at the stages of composting or even at the same stage (Table 2). Although with some exceptions, most strains with typical thermophilic phenotypes, i.e., those unable to grow below $30^{\circ} \mathrm{C}$ or $40^{\circ} \mathrm{C}$ and optimum at $40^{\circ} \mathrm{C}$ or $50^{\circ} \mathrm{C}$, were recovered from THER and, mainly, COOL, whereas those capable to grow over the full range of temperatures tested $\left(20^{\circ} \mathrm{C}-50^{\circ} \mathrm{C}\right)$ were found nearly in all the stages. This may reflect the phenotypic plasticity triggered by the changing composting environment (Moreno et al., 2021).

The sequencing of the 27 fungal strains resulted in four known species of the phylum Ascomycota: Thermomyces lanuginosus (6 strains), Talaromyces thermophilus (renamed as Thermomyces dupontii) (1 strain), Aspergillus fumigatus (17 strains), and Gibellulopsis nigrescens (3 strains) (Supplementary Table 3). All fungal isolates were $\mathrm{Xyl}$, whereas three T. lanuginosus strains and one A. fumigatus exhibited also Cel and Lig activities, which are not common for $T$. lanuginosus. The four fungal species detected have been earlier reported in compost using culturedependent or independent techniques (López-González et al., 2015; Tiquia-Arashiro, 2019), and all except G. nigrescens are well-known as the most frequent thermophilic fungal taxon recovered from such an environment (Hutchinson et al., 2019). $G$. nigrescens has been earlier defined as a typical mesophilic (Zare et al., 2007) for whom no Xyl activity has been reported to date. Most strains grew at temperature ranges of thermophilic fungi $\left(20^{\circ} \mathrm{C}-60^{\circ} \mathrm{C}\right)$, two $A$. fumigatus strains were mesophilic $\left(20-30^{\circ} \mathrm{C}\right)$, and one strain of the same species was a true thermophilic growing only at a temperature greater than $40^{\circ} \mathrm{C}$. Independent-samples Welch $t$ tests revealed no significant differences between species for optimal growth temperature because of the wide range of values exhibited among isolates. However, it was clear that $T$. lanuginosus strains had higher optimal growth temperature (average value of $43^{\circ} \mathrm{C}$ ) than the other species, whose optimal growth temperature never surpassed $40^{\circ} \mathrm{C}$ (Figure 4A). Thermophilic fungi are the ones whose growth temperature ranges from 20 to $62^{\circ} \mathrm{C}$ with the optimum at $35-55^{\circ} \mathrm{C}$, whereas thermotolerant are the ones with a growth temperature range of $20-55^{\circ} \mathrm{C}$ (Maheshwari et al., 2000; Hutchinson et al., 2019). Excluding the A. fumigatus mesophilic isolates, $48 \%$ of the isolates were thermophilic with representatives of all species and $44 \%$ thermotolerant. The different isolates were categorized into six phenotypes according to the optimal temperature for growth and the lignocellulolytic activity, as follows: Xyl strains with optimal growth at 20, 30,40 , or $50^{\circ} \mathrm{C}(\mathrm{X}-20, \mathrm{X}-30, \mathrm{X}-40, \mathrm{X}-50)$, and those having also Cel and Lig activities with optimal growth at 40 or $50^{\circ} \mathrm{C}$ (XCL-40 and XCL-50). The distribution of these phenotypes among the four species is shown in Figure 4B. The widest range of phenotypes was obtained for $T$. lanuginosus, which had representatives of all phenotypes, except X-20. Noteworthy, strains of this species were unique, having optimal growth at $50^{\circ} \mathrm{C}$ and X (Xyl activity) or XCL (Xyl, Cel, and Lig activities). Both $A$. fumigatus and $T$. lanuginosus have a degradation system essential for adaptation during rising temperatures or nutrient limitation in composting materials (Mchunu et al., 2013; Kwon-Chung and Sugui, 2013), which explains their ubiquitous distribution and wide range of phenotypes.

In terms of occurrence of the fungal species at the different composting stages (Figure 5A), A. fumigatus was the most frequently recovered taxon from all stages up to maturation, and it was the unique thermophilic lignocellulolytic fungi in the $\mathrm{RM}$ and COOL. The dominance of this species relates to its capability to survive and propagate successfully under a wide range of environmental conditions (Kwon-Chung and Sugui, 2013). It has been also described as the pioneer thermophilic mycobiota of mushroom compost (Hutchinson et al., 2019). Moreover, it has a strong ability to degrade lignocellulose (Liu et al., 2013; de Gouvêa et al., 2018). The secretome of A. fumigatus has been characterized as having Cel and $\mathrm{Xyl}$ activities, among others, but no ligninases (Liu et al., 2013; Vivek-Ananth et al., 2018; Wang et al., 2018). T. lanuginosus isolates were obtained at the MES and THER and appeared again at the MAT. It has been demonstrated by integrated metaomics that this fungus can secrete a large amount of Xyl during composting and dominated the fungal population in maize straw compost (Zhang et al., 2015). G. nigrescens was found in MES and THER, whereas T. thermophilus was exclusively isolated from the MES. Accordingly, the MES was the only one in which representatives of all four species were present. No thermophilic lignocellulolytic fungus was isolated from the final compost. Moreover, as the composting proceeds, the average optimal growth temperature of the strains increased from 30 to $40^{\circ} \mathrm{C}$, and the range of values was very variable for the strains isolated from MES and MAT (Figure 5B). Similarly, the phenotypes were more diverse at MES and MAT (Figure 5C). It was noticeable that XCL phenotypes, i.e., strains that have Xyl, Cel, and Lig activity, were mainly recovered at the MAT, at which degradation of LIG (7\%) was evidenced (Figure 1D). Antunes et al. (2016), by analyzing the transcriptional profile of genes predicted to be involved in lignocellulose degradation, also demonstrated that Lig activity reaches a peak only at the end of the composting, although no fungal ligninases (Lacs, MnP, and $\mathrm{LiP}$ ) were detected. These results indicate that lignocellulosic biomass deconstruction occurs synergistically and sequentially, 
A

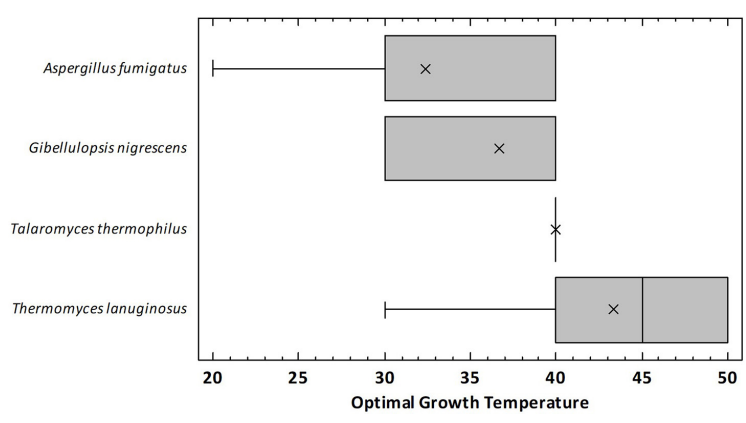

B

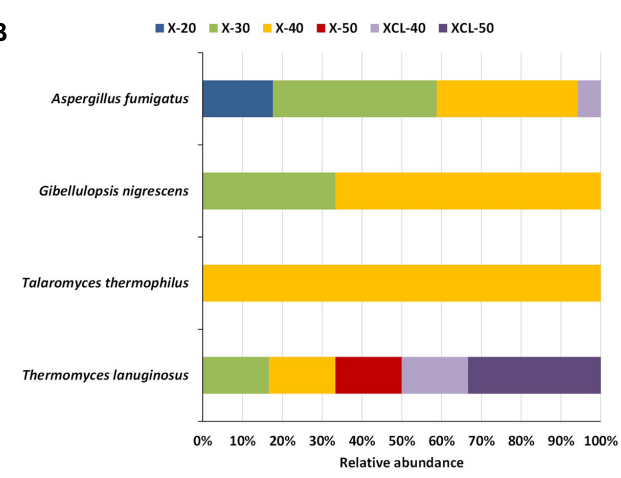

FIGURE 4 | Optimal growth temperatures of the thermophilic fungi isolated from compost. (A) Box-and-whisker plot summarizing the range of optimal growth temperature for the different strains of each species; mean values $(\mathrm{X})$, median (I), and outliers ( $\square$ ) are represented; (B) relative abundance of strains for each species having the optimal growth temperature and enzyme activity: xylanolytic strains with optimal growth at $20^{\circ} \mathrm{C}(X-20), 30^{\circ} \mathrm{C}(X-30), 40^{\circ} \mathrm{C}(X-40)$, and $50^{\circ} \mathrm{C}(X-50)$, and xylanolytic-cellulolytic-ligninolytic strains with optimal growth at $40^{\circ} \mathrm{C}(\mathrm{XCL}-40)$ and $50^{\circ} \mathrm{C}(\mathrm{XCL}-50)$.

A

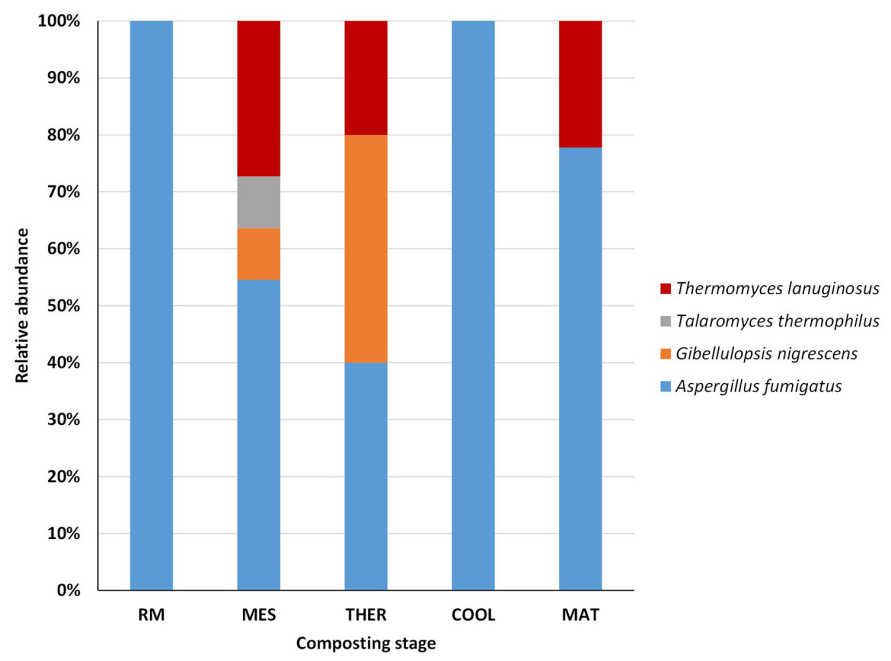

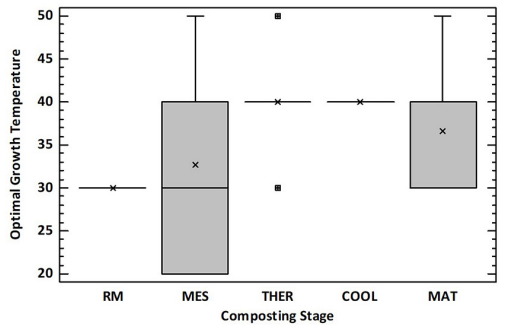

C

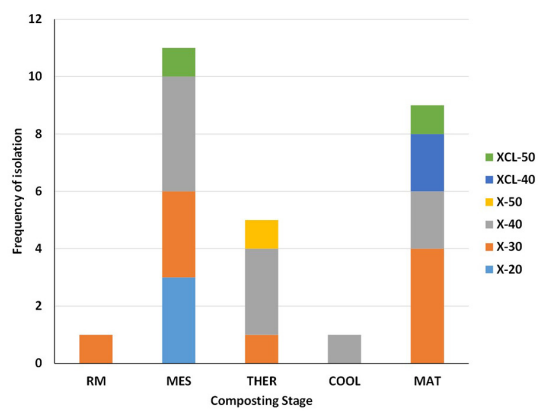

FIGURE 5 | Thermophilic lignocellulolytic fungal strains at the different stages of composting. (A) Relative abundance of the species; (B) box-and-whisker plot summarizing range of optimal growth temperature for the different fungal strains; mean values (X), median (I), and outliers ( $\square$ ) are represented; (C) frequency of isolation of the phenotypes: xylanolytic strains with optimal growth at $20^{\circ} \mathrm{C}(\mathrm{X}-20), 30^{\circ} \mathrm{C}(\mathrm{X}-30), 40^{\circ} \mathrm{C}(\mathrm{X}-40)$, and $50^{\circ} \mathrm{C}(\mathrm{X}-50)$, and xylanolytic-cellulolytic-ligninolytic strains with optimal growth at $40^{\circ} \mathrm{C}(\mathrm{XCL}-40)$ and $50^{\circ} \mathrm{C}$ (XCL-50). Composting stage: RM, raw material; MES, mesophilic; THER, thermophilic; COOL, Cooling; FP, final composting product.

with HC being degraded preferentially to CEL and LIG, as also seen in our study. It is also noteworthy to mention that, as occurred for the bacteria, some strains with the same accession number had different phenotypes even when isolated from the same sampling (Table 3 ). These fungi activate pathways that facilitate adaptation to the composting environment, and they may be able to adapt to several factors including nutrients, gases, water activity, and competing species, besides just high temperature (Maheshwari et al., 2000; Kwon-Chung and Sugui, 2013; Wang et al., 2018), and as the composting proceeds, the strains become more selective. Overall, the results revealed that the thermophilic lignocellulolytic fungal culturome was primarily dominated by A. fumigatus and T. lanuginosus.

\section{Production of Enzymes}

In order to determine the biotechnological potential for lignocellulolytic enzyme production by isolates analyzed in the exploratory analysis previously described, thermophilic bacterial and fungal strains were cultured for 7 days in liquid media containing commercial inducers as carbon source (i.e., CMC, xylan), and the enzymatic activity was measured after reaction of the crude enzymatic extract with the corresponding 
TABLE 3 | Thermal phenotypes of thermophilic lignocellulolytic fungal strains with same accession number detected at the different composting stages: RM, raw material; MES, mesophilic; THER, thermophilic; COOL, cooling; FP, final composting product.

\begin{tabular}{|c|c|c|c|c|c|c|c|c|}
\hline Species & Accession no. & RM & MES & THER & & COOL & & \\
\hline \multirow[t]{2}{*}{ Aspergillus fumigatus } & \multicolumn{2}{|l|}{ GU566217.1 } & 2 & \multicolumn{2}{|l|}{3} & 3 & \multicolumn{2}{|c|}{1} \\
\hline & \multicolumn{2}{|l|}{ GU566217.2 } & & & & & 2 & 3 \\
\hline Gibellulopsis nigrescens & \multicolumn{2}{|l|}{ HE972037.1 } & \multirow[t]{2}{*}{3} & 2 & 3 & & & \\
\hline Thermomyces lanuginosus & JF412006.1 & & & 3 & & & & \\
\hline
\end{tabular}

Thermal phenotypes: (1) range $\left(20^{\circ} \mathrm{C}-50^{\circ} \mathrm{C} / 20^{\circ} \mathrm{C}-60^{\circ} \mathrm{C}\right)$, optimum $\left(20^{\circ} \mathrm{C}, 30^{\circ} \mathrm{C}\right)$; (2) range $\left(20^{\circ} \mathrm{C}-60^{\circ} \mathrm{C}\right)$, optimum $\left(40^{\circ} \mathrm{C}, 50^{\circ} \mathrm{C}\right) ;(3)$ range $\left(30^{\circ} \mathrm{C}-60^{\circ} \mathrm{C}\right)$, optimum $\left(40^{\circ} \mathrm{C}\right.$, $\left.50^{\circ} \mathrm{C}\right)$; (4) range $\left(40^{\circ} \mathrm{C}-60^{\circ} \mathrm{C} 150^{\circ} \mathrm{C}-60^{\circ} \mathrm{C}\right)$, optimum $\left(40^{\circ} \mathrm{C}, 50^{\circ} \mathrm{C}\right)$.

substrate at $50^{\circ} \mathrm{C}$. The bacteria $B$. thermoamylovorans 1141 and $G$. thermodenitrificans 3781 and the fungi T. lanuginosus 5718 and A. fumigatus 5731 were selected for this analysis. This selection was based on previous knowledge on enzyme production or lack of it in literature (Koeck et al., 2014; Winger et al., 2014; de Gouvêa et al., 2018; Verma et al., 2020), the persistence during composting, the set of enzymes detected, and the range and optimal growth temperature for the particular strain. For bacteria, only Xyl production was determined, whereas for the fungi, Cel (CMCase) and ligninases (Lac, LiP, and MnP) were also analyzed along with, as shown in Table 4. All the strains selected were able to grow at a wide range of temperatures, had optimal growth at or greater than $40^{\circ} \mathrm{C}$, and their enzymes were active at $50^{\circ} \mathrm{C}$. These are valuable properties when considering the potential applications of the microorganisms and their enzymes (Bhalla et al., 2013; Bala and Singh, 2019; Patel et al., 2019).

In general, the $\mathrm{Xyl}$ production by bacteria was 10 times lower than that of the fungi, which is common when comparing both microbial groups (Alokika and Singh, 2019). Among the bacteria, G. thermodenitrificans 3781 produced more Xyl $(5.0 \pm 0.3 \mathrm{U} / \mathrm{mL})$ than $B$. thermoamylovorans 1141 $(1.7 \pm 0.0 \mathrm{U} / \mathrm{mL})$. B. thermoamylovorans is able to grow on xylan and the genome sequencing of a strain isolated from biogas plant-predicted genes involved in carbohydrate polymer degradation (Koeck et al., 2014), but no Xyl production has been reported to date; thus, this is the first description of such activity for this species. In contrast, members of Geobacillus are among the bacteria of choice for the levels of production of Xyls with stability at elevated temperatures (Chadha et al., 2019; Verma et al., 2019). For G. thermodenitrificans, Verma et al. (2020) reported Xyl production in the range of values obtained in the present work $(5-10 \mathrm{U} / \mathrm{mL})$ using xylan as carbon source. That value was further improved by optimization up to a maximum of $24 \mathrm{U} / \mathrm{mL}$ using complex substrates such as wheat straw as carbon source (Verma et al., 2020). In addition to Geobacillus species, Caldicellulosiruptor, Thermopolyspora, and several Bacillus species have been reported to be the more effective thermophilic bacteria for the production of thermostable Xyl (Bala and Singh, 2019; Chadha et al., 2019).

The two fungi produced all the enzymes tested, at reasonable levels of activity for $\mathrm{Xyl}$ in comparison to values reported in literature (Liu et al., 2013; de Gouvêa et al., 2018; Chadha et al., 2019) and very low for Cel and ligninases. This result was surprising, especially in the case of T. lanuginosus, known as a hyperproducer of thermostable Xyls that have no Cel and ligninase activity (Winger et al., 2014; Chadha et al., 2019). The production of Xyl by T. lanuginosus 5718 was low $(37.1 \pm 2.4 \mathrm{U} / \mathrm{mL})$ in comparison to the reported values exhibited by some strains under optimized conditions. T. lanuginosus strains isolated from different environments vary in their Xyl production capacity, but in general, high Xyl activity is obtained, and optimization allows to dramatically increase Xyl activity. For example, T. lanuginosus isolated from decaying wood produced $132.5 \mathrm{U} / \mathrm{mL}$ using a combination of optimization approaches, whereas strain SSBP isolated from soil produced 3,575 U/mL, the highest reported activity of any known Xyl to date (Winger et al., 2014; Alokika and Singh, 2019; Chadha et al., 2019). The Cel $(0.02 \pm 0.01 \mathrm{U} / \mathrm{mL}), \mathrm{Lac}(1.0 \pm 0.2 \mathrm{U} / \mathrm{mL}), \mathrm{LiP}$ $(0.3 \pm 0.1 \mathrm{U} / \mathrm{mL})$, and $\mathrm{MnP}(0.3 \pm 0.1 \mathrm{U} / \mathrm{mL})$ activities exhibited by $T$. lanuginosus 5718 , although being almost negligible, require further research as these enzymes have not been reported earlier for the species. Other thermophiles also exhibit very low values for Cels and ligninases as discussed below in the case of A. fumigatus. Gene expression assays are being conducted to validate the singular enzymatic activities encountered

TABLE 4 | Production of enzymes by selected thermophilic isolates.

\begin{tabular}{|c|c|c|c|c|c|c|c|}
\hline \multirow[t]{2}{*}{ Strain } & \multicolumn{2}{|c|}{ Growth temperature $\left({ }^{\circ} \mathrm{C}\right)$} & \multicolumn{5}{|c|}{ Enzymatic activity (U/mL) } \\
\hline & Range & Optimal & Cellulase & Xylanase & Lac & LiP & $\mathrm{MnP}$ \\
\hline Bacillus thermoamylovorans 1141 & $30-60$ & 40 & nd & $1.7 \pm 0.0$ & nd & nd & nd \\
\hline Geobacillus thermodenitrificans 3781 & $20-60$ & 50 & nd & $5.0 \pm 0.3$ & nd & nd & nd \\
\hline Thermomyces lanuginosus 5718 & $20-60$ & 50 & $0.02 \pm 0.01$ & $37.1 \pm 2.4$ & $1.0 \pm 0.2$ & $0.3 \pm 0.1$ & $0.3 \pm 0.1$ \\
\hline Aspergillus fumigatus 5731 & $40-60$ & 40 & $0.01 \pm 0.00$ & $54.6 \pm 4.8$ & $0.8 \pm 0.3$ & $0.2 \pm 0.0$ & $1.4 \pm 0.4$ \\
\hline
\end{tabular}

nd, not determined. 
in T. lanuginosus 5718. A. fumigatus 5731 produced higher levels of Xyl $(54.6 \pm 4.8 \mathrm{U} / \mathrm{mL})$ than $T$. lanuginosus 5718 , but the production of Cel $(0.01 \pm 0.00 \mathrm{U} / \mathrm{mL}), \mathrm{Lac}(0.8 \pm 0.3 \mathrm{U} / \mathrm{mL})$, $\mathrm{LiP}(0.2 \pm 0.0 \mathrm{U} / \mathrm{mL})$, and $\mathrm{MnP}(1.4 \pm 0.4 \mathrm{U} / \mathrm{mL})$ was similar, with very low values. For $A$. fumigatus, the production of all the enzymes has been reported to be very dependent on the carbon source used and the strain. The enzyme activities obtained are similar to those reported by Liu et al. (2013) that found a maximum Xyl activity of $15 \mathrm{U} / \mathrm{mL}$ after 2 days' incubation of $A$. fumigatus $\mathrm{Z} 5$ on rice straw, whereas very low values of ligninases were detected. In contrast, de Gouvêa et al. (2018) obtained maximum activities of Cel (0.032 $\mathrm{U} / \mathrm{mL})$ and $\mathrm{Xyl}(10.82 \mathrm{U} / \mathrm{mL})$ from steam-exploded bagasse. Although the analysis of the secretome revealed the presence of LIG-depolymerizing enzymes, no results on production were reported. The production of enzymes by A. fumigatus 5731 requires further optimization in order to reach values comparable to the production found by others. For example, A. fumigatus CWSF-7 produces 1.9 U/mL Cel (Mohapatra et al., 2018), whereas Lin et al. (2017) obtained high titers of Xyl (91.9 U/mL) and Cel $(5.61 \mathrm{U} / \mathrm{mL})$ activity after optimization when $1 \%$ barley straw was used as the carbon source.

\section{CONCLUSION}

The present study provided insights into thermophilic culturome inhabiting composting material, which is involved in the degradation of lignocellulose. The study demonstrated that the whole fungal thermophilic population exhibits lignocellulosedegrading activity, of which only four species of Ascomycota are responsible. In the case of bacteria, $8-10 \%$ of the thermophilic population had this trait, although exclusively for HC degradation (xylan-degrading), which was due to a wider diversity dominated by representatives of the phylum Firmicutes. A common feature for bacteria and fungi was the capability to grow at a wide range of temperatures, having only a few representatives being strictly thermophilic. That allows them to survive and remain metabolically active over all stages of composting, playing a key role in the breakdown of $\mathrm{HC}$ during the entire process, with the degradation of CEL and LIG restricted to the activity of a few thermophilic fungi that appear at

\section{REFERENCES}

Ahmed, I., Yokota, A., Yamazoe, A., and Fujiwara, T. (2007). Proposal of Lysinibacillus boronitolerans gen. nov. sp. nov., and transfer of Bacillus fusiformis to Lysinibacillus fusiformis comb. nov. and Bacillus sphaericus to Lysinibacillus sphaericus comb. nov. Int. J. Syst. Evol. Micr. 57, 1117-1125. doi: 10.1099/ijs.0.63867-0

Alokika, S., and Singh, B. (2019). Production, characteristics, and biotechnological applications of microbial xylanases. Appl. Microbiol. Biotechnol. 103, 87638784. doi: 10.1007/s00253-019-10108-6

Antunes, L., Martins, L., Pereira, R., Thomas, A., Barbosa, D., Lemos, L., et al. (2016). Microbial community structure and dynamics in thermophilic composting viewed through metagenomics and metatranscriptomics. Sci. Rep. 6:38915. doi: 10.1038/srep38915

Bala, A., and Singh, B. (2019). Cellulolytic and xylanolytic enzymes of thermophiles for the production of renewable biofuels. Renew. Energy 136, 1231-1244. doi: 10.1016/j.renene.2018.09.100 the end of the process. Likewise, the presence of phenotypes not previously described (either for thermal tolerance or for enzyme activities) within the species, besides the fact that many species evolve distinctly at the stages of composting, opens up many questions related to the mechanisms responsible for such adaptations to the changing composting ecosystem. The strains obtained in this work are a valuable resource to determine such mechanisms. Finally, the study selected some candidates representing a promising source of thermozymes with important biotechnological applications whose enzyme characteristics and production optimization remain to be determined.

\section{DATA AVAILABILITY STATEMENT}

The datasets presented in this study can be found in online repositories. This data can be found in López et al. (2021).

\section{AUTHOR CONTRIBUTIONS}

ML: formal analyses, investigation, supervision, and writingreview and editing. MJ: investigation and writing-original draft preparation. JL-G: methodology, formal analyses, and writingoriginal draft preparation. ME-G, MM-G, and AT: methodology and investigation. FS-E: methodology, visualization, and writing-original draft preparation. All authors contributed to the article and approved the submitted version.

\section{FUNDING}

This work was financially supported by the Spanish Ministerio de Economía y Competitividad through the projects AGL200908405 and AGL2012-36434.

\section{SUPPLEMENTARY MATERIAL}

The Supplementary Material for this article can be found online at: https://www.frontiersin.org/articles/10.3389/fmicb. 2021.697480/full\#supplementary-material

Bhalla, A., Bansal, N., Kumar, S., Bischoff, K. M., and Sani, R. K. (2013). Improved lignocellulose conversion to biofuels with thermophilic bacteria and thermostable enzymes. Bioresour. Technol. 128, 751-759. doi: 10.1016/j. biortech.2012.10.145

Bhattacharya, A., and Pletschke, B. (2014). "Thermophilic bacilli and their enzymes in composting," in Composting for Sustainable Agriculture. Sustainable Development and Biodiversity, Vol. 3, ed. D. Maheshwari (Cham: Springer), doi: 10.1007/978-3-319-08004-8_6

Bugg, T. D., Ahmad, M., Hardiman, E. M., and Singh, R. (2011). The emerging role for bacteria in lignin degradation and bio-product formation. Curr. Opin. Biotechnol. 22, 394-400. doi: 10.1016/j.copbio.2010. 10.009

Camarero, S., Sarkar, S., Ruiz-Dueñas, F. J., Martínez, M. J., and Martínez, A. T. (1999). Description of a versatile peroxidase involved in the natural degradation of lignin that has both manganese peroxidase and lignin peroxidase substrate interaction sites. J. Biol. Chem. 274, 10324-10330. doi: 10.1074/jbc.274.15. 10324 
Chadha, B. S., Kaur, B., Basotra, N., Tsang, A., and Pandey, A. (2019). Thermostable xylanases from thermophilic fungi and bacteria: current perspective. Bioresour. Technol. 277, 195-203. doi: 10.1016/j.biortech.2019.01.044

Chadha, S., and Kale, S. P. (2015). Simple fluorescence-based high throughput cell viability assay for filamentous fungi. Lett. Appl. Microbiol. 61, 238-244. doi: 10.1111/lam.12460

Chauhan, P. S., Goradia, B., and Saxena, A. (2017). Bacterial laccase: recent update on production, properties and industrial applications. 3 Biotech 7:323. doi: 10.1007/s13205-017-0955-7

de Gouvêa, P. F., Bernardi, A. V., Gerolamo, L. E., de Souza Santos, E., RiañoPachón, D. M., Uyemura, S. A., et al. (2018). Transcriptome and secretome analysis of Aspergillus fumigatus in the presence of sugarcane bagasse. BMC Genomics 19:232. doi: 10.1186/s12864-018-4627-8

Di Piazza, S., Houbraken, J., Meijer, M., Cecchi, G., Kraak, B., Rosa, E., et al. (2020). Thermotolerant and thermophilic mycobiota in different steps of compost maturation. Microorganisms 8:880. doi: 10.3390/microorganisms 8060880

Estrella-González, M. J., Suárez-Estrella, F., Jurado, M. M., López, M. J., LópezGonzález, J. A., Siles-Castellano, A. B., et al. (2020). Uncovering new indicators to predict stability, maturity and biodiversity of compost on an industrial scale. Bioresour. Technol. 313:123557. doi: 10.1016/j.biortech.2020.123557

Fidalgo, C., Riesco, R., Henriques, I., Trujillo, M. E., and Alves, A. (2016). Microbacterium diaminobutyricum sp. nov., isolated from Halimione portulacoides, which contains diaminobutyric acid in its cell wall, and emended description of the genus Microbacterium. Int. J. Syst. Evol. Micr. 66, 4492-4500. doi: 10.1099/ijsem.0.001379

Freitag, M., and Morrell, J. J. (1992). Decolorization of the polymeric dye Poly R-478 by wood-inhabiting fungi. Can. J. Microbiol. 38, 811-822. doi: 10.1139/ m92-133

Gavande, P. V., Basak, A., Sen, S., Lepcha, K., Murmu, N., Rai, V., et al. (2021). Functional characterization of thermotolerant microbial consortium for lignocellulolytic enzymes with central role of Firmicutes in rice straw depolymerization. Sci. Rep. 11:3032. doi: 10.1038/s41598-021-82163-x

Gerhardt, P., Murray, R. G. E., Wood, W. A., and Krieg, N. R. (eds) (1994). Methods for General and Molecular Bacteriology. Washington, DC: American Society for Microbiology.

Harindintwali, J. D., Zhou, J., and Yu, X. (2020). Lignocellulosic crop residue composting by cellulolytic nitrogen-fixingbacteria: a novel tool for environmental sustainability. Sci. Total Environ. 715:136912. doi: 10.1016/j. scitotenv.2020.136912

He, L., Bickerstaff, G. F., Paterson, A., and Buswell, J. A. (1993). Purification and partial characterization of two xylanases that differ in hydrolysis of soluble and insoluble xylan fractions. Enzyme Microb. Technol. 15, 13-18. doi: 10.1016/ 0141-0229(93)90110-N

Hemati, A., Aliasgharzad, N., and Khakvar, R. (2018). In vitro evaluation of lignocellulolytic activity of thermophilic bacteria isolated from different composts and soils of Iran. Biocatal. Agric. Biotechnol. 14, 424-430. doi: 10. 1016/j.bcab.2018.04.010

Hutchinson, M. I., Powell, A. J., Herrera, J., and Natvig, D. O. (2019). "New perspectives on the distribution and roles of thermophilic fungi," in Fungi in Extreme Environments: Ecological Role and Biotechnological Significance, eds S. M. Tiquia-Arashiro and M. Grube (Cham: Springer), 59-80. doi: 10.1007/ 978-3-030-19030-9_4

Ince, O., Ozbayram, E. G., Akyol, Ç, Erdem, E. I, Gunel, G., and Ince, B. (2020). Bacterial succession in the thermophilic phase of composting of anaerobic digestates. Waste Biomass Valori. 11, 841-849. doi: 10.1007/s12649-0180531-3

Insam, H., and de Bertoldi, M. (2007). "Microbiology of the composting process," in Compost Science and Technology. Waste Manage Series, Vol. 8, eds L. F. Díaz, M. de Bertoldi, W. Bidlingmaier, and E. Stentiford (Amsterdam: Elsevier), 25-48.

Janshekar, M., Haltmeier, T., and Brown, C. (1982). Fungal degradation of pine and straw alkali lignins. Eur. J. Appl. Microbiol. Biotechnol. 14, 174-181. doi: 10.1007/BF00497896

Jurado, M., López, M. J., Suárez-Estrella, F., Vargas-García, M. C., López-González, J. A., and Moreno, J. (2014). Exploiting composting biodiversity: study of the persistent and biotechnologically relevant microorganisms from lignocellulosebased composting. Bioresour. Technol 162, 283-293. doi: 10.1016/j.biortech. 2014.03.145
Kauri, T., and Kushner, D. J. (1988). Detection of cellulolytic activity of bacteria and fungi growing on agar surfaces. Biotechnol. Tech. 2, 149-152. doi: 10.1007/ BF01875755

Kim, D. Y., Shin, D. H., Jung, S., Kim, H., Lee, J. S., Cho, H. Y., et al. (2014). Novel alkali-tolerant GH10 endo- $\beta$-1,4-xylanase with broad substrate specificity from Microbacterium trichothecenolyticum HY-17, a gut bacterium of the mole cricket Gryllotalpa orientalis. J. Microbiol. Biotechnol. 24, 943-953. doi: 10.4014/ jmb.1405.05032

Kirk, T. K., Croan, S., Tien, M., Murtagh, K. E., and Farrell, R. L. (1986). Production of multiple ligninases by Phanerochaete chrysosporium: effect of selected growth conditions and use of a mutant strain. Enzyme Microb. Technol. 8, 27-32. doi: 10.1016/0141-0229(86)90006-2

Koeck, D. E., Wibberg, D., Maus, I., Winkler, A., Albersmeier, A., Zverlov, V. V., et al. (2014). First draft genome sequence of the amylolytic Bacillus thermoamylovorans wild-type strain 1A1 isolated from a thermophilic biogas plant. J. Biotechnol. 192, 154-155. doi: 10.1016/j.jbiotec.2014.09.017

Kwon-Chung, K. J., and Sugui, J. A. (2013). Aspergillus fumigatuswhat makes the species a ubiquitous human fungal pathogen? PLoS Pathog. 9:e1003743. doi: 10.1371/journal.ppat.1003743

Langarica-Fuentes, A., Handley, P. S., Houlden, A., Fox, G., and Robson, G. D. (2014). An investigation of the biodiversity of thermophilic and thermotolerant fungal species in composts using culture-based and molecular techniques. Fungal Ecol. 11, 132-144. doi: 10.1016/j.funeco.2014.05.007

Larkin, M. A., Blackshields, G., Brown, N. P., Chenna, R., McGettigan, P. A., McWilliam, H., et al. (2007). Clustal W and Clustal X version 2.0. Bioinformatics 23, 2947-2948. doi: 10.1093/bioinformatics/btm 404

Lin, C., Shen, Z., and Qin, W. (2017). Characterization of xylanase and cellulase produced by a newly isolated Aspergillus fumigatus N2 and its efficient saccharification of barley straw. Appl. Biochem. Biotechnol. 182, 559-569. doi: 10.1007/s12010-016-2344-9

Liu, D., Li, J., Zhao, S., Zhang, R., Wang, M., Miao, Y., et al. (2013). Secretome diversity and quantitative analysis of cellulolytic Aspergillus fumigatus Z5 in the presence of different carbon sources. Biotechnol. Biofuels 6, 1-16. doi: 10.1186/ 1754-6834-6-149

López, M. J., Jurado, M. M., López-González, J. A., and Suárez-Estrella, F. (2021). Thermophilic lignocellulolytic microorganisms in composting. Mendeley Data V1. doi: 10.17632/265tjt9f4m.1

López-González, J. A., López, M. J., Vargas-García, M. C., Suárez-Estrella, F., Jurado, M. M., and Moreno, J. (2013). Tracking organic matter and microbiota dynamics during the stages of lignocellulosic waste composting. Bioresour. Technol. 146, 574-584. doi: 10.1016/j.biortech.2013.07.122

López-González, J. A., Vargas-García, M. C., López, M. J., Suárez-Estrella, F., Jurado, M. M., and Moreno, J. (2015). Biodiversity and succession of mycobiota associated to agricultural lignocellulosic waste-based composting. Bioresour. Technol. 187, 305-313. doi: 10.1016/j.biortech.2015.03.124

Maheshwari, R., Bharadwaj, G., and Bhat, M. K. (2000). Thermophilic fungi: their physiology and enzymes. Microbiol. Mol. Biol. Rev. 64, 461-488. doi: 10.1128/ mmbr.64.3.461-488.2000

Mchunu, N. P., Permaul, K., Rahman, A. Y. A., Saiot, J. A., Singh, S., and Alam, M. (2013). Xylanase superproducer: genome sequence of a compost-loving thermophilic fungus, Thermomyces lanuginosus strain SSBP. Genome Announc. 1:e388-13. doi: 10.1128/genomeA.00388-13

Miller, G. L. (1959). Use of dinitrosalicylic acid reagent for determination of reducing sugar. Anal. Chem. 31, 426-428. doi: 10.1021/ac60147a030

Minana-Galbis, D., Pinzon, D. L., Loren, J. G., Manresa, A., and Oliart-Ros, R. M. (2010). Reclassification of Geobacillus pallidus (Scholz et al. 1988) Banat et al. 2004 as Aeribacillus pallidus gen. nov., comb. nov. Int. J. Syst. Evol. Microbiol. 60, 1600-1604. doi: 10.1099/ijs.0.003699-0

Mohapatra, S., Padhy, S., Mohapatra, P. K. D., and Thatoi, H. N. (2018). Enhanced reducing sugar production by saccharification of lignocellulosic biomass, Pennisetum species through cellulase from a newly isolated Aspergillus fumigatus. Bioresour. Technol. 253, 262-272. doi: 10.1016/j.biortech.2018.01. 023

Moreno, J., López-González, J. A., Arcos-Nievas, M. A., Suárez-Estrella, F., Jurado, M. M., Estrella-González, M. J., et al. (2021). Revisiting the succession of microbial populations throughout composting: a matter of thermotolerance. Sci. Total Environ. 773:145587. doi: 10.1016/j.scitotenv.2021.145587 
Orth, A. B., Royse, D. J., and Tien, M. (1993). Ubiquity of lignin-degrading peroxidases among various wood-degrading fungi. Appl. Environ. Microbiol. 59, 4017-4023. doi: 10.1128/AEM.59.12.4017-4023.1993

Paredes, C., Roig, A., Bernal, M. P., Sánchez-Monedero, M. A., and Cegarra, J. (2000). Evolution of organic matter and nitrogen during co-composting of olive mill wastewater with solid organic wastes. Biol. Fertil. Soils 32, 222-227. doi: $10.1007 /$ s003740000239

Patel, A. K., Singhania, R. R., Sim, S. J., and Pandey, A. (2019). Thermostable cellulases: current status and perspectives. Bioresour. Technol. 279, 385-392. doi: 10.1016/j.biortech.2019.01.049

Qiao, C., Penton, C. R., Liu, C., Shen, Z., Ou, Y., Liu, Z., et al. (2019). Key extracellular enzymes triggered high-efficiency composting associated with bacterial community succession. Bioresour. Technol. 288:121576. doi: 10.1016/ j.biortech.2019.121576

Schaub, S. M., and Leonard, J. J. (1996). Composting: an alternative waste management option for food processing industries. Trends Food Sci. Technol. 7, 263-268. doi: 10.1016/0924-2244(96)10029-7

Steger, K., Jarvis, A. T., Romantschuk, M., and Sundh, I. (2007). Effects of differing temperature management on development of Actinobacteria populations during composting. Res. Microbiol. 158, 617-624. doi: 10.1016/j.resmic.2007. 05.006

Tamura, K., Peterson, D., Peterson, N., Stecher, G., Nei, M., and Kumar, S. (2011). MEGA5: molecular evolutionary genetics analysis using maximum likelihood, evolutionary distance, and maximum parsimony methods. Mol. Biol. Evol. 28, 2731-2739. doi: 10.1093/molbev/msr121

Tiquia-Arashiro, S. M. (2019). "Thermophilic fungi in composts: their role in composting and industrial processes," in Fungi in Extreme Environments: Ecological Role and Biotechnological Significance, eds S. Tiquia-Arashiro and M. Grube (Cham: Springer), doi: 10.1007/978-3-030-1 9030-9_29

Vega, B., Liberti, D., Harmon, P. F., and Dewdney, M. M. (2012). A rapid resazurinbased microtiter assay to evaluate QoI sensitivity for Alternaria alternata isolates and their molecular characterization. Plant Dis. 96, 1262-1270.

Verma, D., Kumar, R., and Satyanarayana, T. (2019). "Diversity in xylan-degrading prokaryotes and xylanolytic enzymes and their bioprospects," in Microbial Diversity in Ecosystem Sustainability and Biotechnological Applications, eds T. Satyanarayana, S. Das, and B. Johri (Singapore: Springer), doi: 10.1007/978981-13-8487-5_14

Verma, R., Bhalla, A., and Kumar, S. (2020). Valorization of lignocellulosic residues for cost-effective production of thermo-alkali-stable xylanase by Geobacillus thermodenitrificans X1 of Indian Himalayan Hot Spring. Waste Biomass Valori. 11, 1205-1215. doi: 10.1007/s12649-018-0402-y

Villar, I., Alves, D., Garrido, J., and Mato, S. (2016). Evolution of microbial dynamics during the maturation phase of the composting of different types of waste. Waste Manag. 54, 83-92. doi: 10.1016/j.wasman.2016. 05.011

Vivek-Ananth, R. P., Mohanraj, K., Vandanashree, M., Jhingran, A., Craig, J. P., and Samal, A. (2018). Comparative systems analysis of the secretome of the opportunistic pathogen Aspergillus fumigatus and other Aspergillus species. Sci. Rep. 8:6617. doi: 10.1038/s41598-018-25016-4
Wang, D., Zhang, L., Zou, H., and Wang, L. (2018). Secretome profiling reveals temperature-dependent growth of Aspergillus fumigatus. Sci. China Life Sci. 61, 578-592. doi: 10.1007/s11427-017-9168-4

Wei, Z., Huang, S., Zhang, Y., Li, H., and Zhou, S. (2017). Characterization of extracellular polymeric substances produced during nitrate removal by a thermophilic bacterium Chelatococcus daeguensis TAD1 in batch cultures. RSC Adv. 7, 44265-44271. doi: 10.1039/C7RA08147B

Weisburg, W. G., Barns, S. M., Pelletier, D. A., and Lane, D. J. (1991). 16S ribosomal DNA amplification for phylogenetic study. J. Bacteriol. 173, 697-703. doi: 10.1128/jb.173.2.697-703.1991

White, T. J., Bruns, T., Lee, S., and Taylor, J. (1990). Amplification and direct sequencing of fungal ribosomal RNA genes for phylogenetics. PCR Protoc. Guide Methods Appl. 18, 315-322. doi: 10.1016/b978-0-12-372180-8.50042-1

Winger, A. M., Heazlewood, J. L., Chan, L. J. G., Petzol, C. J., Permaul, K., and Singh, S. (2014). Secretome analysis of the thermophilic xylanase hyperproducer Thermomyces lanuginosus SSBP cultivated on corn cobs. J. Ind. Microbiol. Biotechnol. 41, 1687-1696. doi: 10.1007/s10295-014-1509-1

Xiao, Y., Zeng, G. M., Yang, Z. H., Shi, W. J., Huang, C., Fan, C. Z., et al. (2009). Continuous thermophilic composting (CTC) for rapid biodegradation and maturation of organic municipal solid waste. Bioresour. Technol. 100, 4807-4813. doi: 10.1016/j.biortech.2009.05.013

Yoon, J. H., Kang, S. J., Im, W. T., Lee, S. T., and Oh, T. K. (2008). Chelatococcus daeguensis sp. nov., isolated from wastewater of a textile dye works, and emended description of the genus Chelatococcus. Int. J. Syst. Evol. Microbiol. 58, 2224-2228. doi: 10.1099/ijs.0.65291-0

Zare, R., Gams, W., Starink-Willemse, M., and Summerbell, R. C. (2007). Gibellulopsis, a suitable genus for Verticillium nigrescens, and Musicillium, a new genus for $V$. theobromae. Nova Hedwigia 85, 463-490. doi: 10.1127/00295035/2007/0085-0463

Zhang, L., Ma, H., Zhang, H., Xun, L., Chen, G., and Wang, L. (2015). Thermomyces lanuginosus is the dominant fungus in maize straw composts. Bioresour. Technol. 197, 266-275. doi: 10.1016/j.biortech.2015.08.089

Conflict of Interest: The authors declare that the research was conducted in the absence of any commercial or financial relationships that could be construed as a potential conflict of interest.

Publisher's Note: All claims expressed in this article are solely those of the authors and do not necessarily represent those of their affiliated organizations, or those of the publisher, the editors and the reviewers. Any product that may be evaluated in this article, or claim that may be made by its manufacturer, is not guaranteed or endorsed by the publisher.

Copyright (c) 2021 López, Jurado, López-González, Estrella-González, MartínezGallardo, Toribio and Suárez-Estrella. This is an open-access article distributed under the terms of the Creative Commons Attribution License (CC BY). The use, distribution or reproduction in other forums is permitted, provided the original author(s) and the copyright owner(s) are credited and that the original publication in this journal is cited, in accordance with accepted academic practice. No use, distribution or reproduction is permitted which does not comply with these terms. 